\section{Landscape a l' americaine}

The Origin of Landscapes: A Synthesis of Geomorphology. By H. F. Garner. Pp. xx +734 . (Oxford University Press: London and New York, October 1974.) $£ 10.75$.

THus long and well-produced text is designed for use at US college level and presumably, therefore, for undergraduates in European universities. In it the author attempts to combine geology, geomorphology, climatology, botany and other branches of natural science in a synthesis of landscape study. The resultant theme seems to be halfway between physical geography in the European sense and physical geology in the American sense.

The presentation of the geomorphic subject matter is said by the author to be "at once new and not new" insofar as it emphasises the relationships of processes and treats any particular process in its several environments: for example, the effect of running water at the surface is discussed in humid, arid, and glacial contexts, and again with respect to alternating environmental conditions. The general theme reflects the genesis of landforms by associations with environmental systems and through the substitution of one system for another in time and space. Thus, the essential theoretical thread that binds together the otherwise detached concepts is the fact that most landscapes are the products of environmental sequence.

The main body of the text opens with a chapter on the concepts of geomorphic theory and the development of geomorphic ideas. The discussion is lively and stimulating but needs some revision. For example. the author thinks the peneplain was the ultimate landform in the Davisian cycle whereas it was penultimate; he considers that downstream increase in the velocity of rivers augments their erosive power whereas, presumably, the velocity is increased because of relative decrease in bed friction or erosional contact.

This introductory matter is strengthened by the succeeding chapter on geomorphic techniques which summarises modern advances. That is followed by a long account, forming nearly oneseventh of the book, on recent tectonic theories and findings, including plate tectonics, mid-oceanic ridges and sea floor spreading. The excellence and detail of this well-illustrated synopsis are not maintained in the next chapter which deals with "surficial geomorphic patterns" and contains inter alia a rather elementary account of the atmosphere and of the circulation of the oceans.

The chief superficial landscape sys- tems are discussed. Humid, vegetated environments- - the Davisian normare given far less textual space than are glaciation and glacial landforms, arid non-vegetated systems or alternating arid-humid environments. Coasts and mountains are treated separately as polygenetic landscapes, the former being the zone of contact between two distinct environments and the latter the areas within which internal uplift conflicts markedly with external erosion.

The closing chapters consider the application of geomorphological techniques to the theoretical reconstruction of ancient buried landscapes, and the nature of the various physical problems associated with alterations of the present day environment. The volume ends with a glossary of basal geomorphological terms which will be useful for beginners, and a comprehensive index that includes reference to the many striking illustrations, about 600 in all.

An attractive and lavish production, with many progressive ideas, this volume is a welcome and worthwhile addition to educational geomorphological literature. It is not easy, however, for a European to assess it with equanimity. The author thinks that

\section{Borers, foulers, sprats, and mangroves}

The Biology of Estuaries and Coastal Waters. By E. J. Perkins. Pp. ix +678. (Academic: London and New York, 1974.) £14.60; $\$ 37.35$.

Perkins' attempt to review comprehensively the biology of estuaries and coastal waters has resulted in a large book. The first fifth is introductory and covers the basic physico-chemical and dynamic characteristics of inshore waters; but the treatment is terse and fragmentary. No reader is likely to benefit from such short sections on tides and waves; and the hydrography of estuaries-so fundamental to what follows-surely merits thorough treatment.

The biota of the various habitats are described in the middle portion of the book, and environmental factors which limit distributions and/or vital activities are discussed. Microorganisms, plants and animals are covered, so most readers will find new information here. There are inconsistencies in approach: discussion is limited largely to estuarine plankton although rocky shores are mainly non-estuarine. And it seems a pity that the ecologically significant differences in the timing of primary production cycles in oceanic and neritic water masses could not have been mentioned. Rocky shore zonation is introduced principally by reference to one British locality but, as coverage (here and throughout the book) is by no means confined to the British Isles, a generalised Stephensonian scheme
Great Britain is "an island near the Gulf Stream" and in his index Europe receives 17 entries against 33 for Ecuador, 31 for Venezuela and 25 for Peru. Such a locational bias can be understood as the text is intended for American colleges; but less understandable are the frequent misuse-for depicting spatial distributions-of Mercator's cylindrical world projection (with each pole exaggerated in length 24,000 times to equal the equator), and the occasional textual error, such as Gibralter, duracrust, mollasse, and cannons (for canons of landscape evolution). Occasionally, too, the language probably becomes rather too-American or too askew to appeal to European taste. Is there arising an Old World-New World linguistic divide? We read that "coastal geomorphic systems . . . exist where the sea embraces the land, lingeringly, and often with what might well pass for passion"; that "the tectonics of plates is a fascinating jigsaw puzzle with many of the nobler attributes of a floating crap game". Whereas the pundits of the Oxford Press seem ignorant of the evils of Mercator, they are obviously experts at crap.

Robert P. Beckinsale

would have been more appropriate: the pages on Australian zone-formers may then have integrated better. The superficial approach can be appreciated when it is considered that, although sedimentary beach biota include salt marshes and mangroves the description of this group is restricted to 15 pages.

Even so, the author's interest in the interactions between man and the coastal environment is apparent, and that theme at least is expanded. The detrimental activities of borers and foulers are covered, as is the production of those organisms which man uses for food. Shellfish, except for tropical prawns, are treated fairly fully; but fish, as elsewhere in the book, receive scant attention. Thus the sprat, with an annual catch of up to 100,000 tons in the estuaries and embayments of the North Sea, gets only an incidental mention, and the importance of estuaries as herring and sprat nursery areas is omitted.

The chapter on pollution is somewhat philosophical, but waste disposal and management are both discussed. Prominence is given to the high standards laid down by the United States Federal Water Quality Administration, which contrast with the low standards (except for radioactive waste disposal) acceptable in the UK.

By opting for breadth the author opens himself to criticism for the brevity with which many topics are treated, especially in those fields in 